\title{
Evaluation of the Simplified Dynamic Wave, Diffusion Wave and the Full Dynamic Wave Flood Routing Models
}

\author{
John Perdikaris ${ }^{1}$, Bahram Gharabaghi ${ }^{2} \&$ Ramesh Rudra $^{2}$ \\ ${ }^{1}$ Civil Engineering Department, Ryerson University, Toronto, Canada \\ ${ }^{2}$ School of Engineering, University of Guelph, Guelph, Canada \\ Correspondence: Bahram Gharabaghi, School of Engineering, University of Guelph, Guelph, ON., N1G 2W1, \\ Canada. Tel: 1-519-824-4120 Ext: 58451.E-mail: bgharaba@uoguelph.ca
}
Received: March 10, 2018
Accepted: March 22, 2018
Online Published: May 4, 2018
doi:10.5539/esr.v7n2p14
URL: https://doi.org/10.5539/esr.v7n2p14

The research is financed by Natural Science and Engineering Council of Canada (NSERC).

\begin{abstract}
The accuracy of prediction and ease of use of the three popular flood routing models; simplified dynamic Wave, diffusion wave, and full dynamic wave were evaluated. The models were evaluated along a reach of the Credit River Watershed, in Southern Ontario, Canada. The simplified dynamic wave model showed better accuracy and easier formulation when compared against the diffusion wave and the full dynamic wave models. Indicating that the simplified dynamic wave model can be applied to reaches where the diffusion wave and the full dynamic wave models may not be applicable. The principle novel contributions of the paper are (a) the extension of the flood routing formulations by Keskin and Agiralioglu, (b) the use of a prismatic channel and floodplain with varying top-widths, (c) the validation of the methodology through the application of an event simulation to an actual river reach, and (d) comparison of the modeling results to those obtained using the full dynamic wave model and the diffusion wave models.
\end{abstract}

Keywords: channel flow, floodplain flow, finite differences, prismatic channels, transmission losses

\section{Introduction}

Flow routing is a procedure to determine the time and magnitude of flow at a point on a watercourse from known or assumed hydrographs at one or more points upstream. When applied to flows in irregular shaped channels, for example, rivers with inundated floodplain zones, the exercise becomes very complex (Perdikaris et al., 2011). If the channel and floodplain are treated as a single composite section, flow discharges are generally under-estimated. If the channel and floodplain are treated separately, then the flow discharges are generally over-estimated (Wormleaton and Hadjipanos, 1982). Successful applications of dynamic wave flood routing models are not only dependent on proper initial and boundary conditions being established, but may also require certain modifications to the original data sets (Kouwen, 1984).

The Saint Venant equations, first developed by Barre de Saint-Venant in 1871, describe the one-dimensional unsteady open channel flow. In practice, flood routing is rarely achieved by directly solving the complete SaintVenant equations (de Saint Venant, 1871). Methods have been developed to provide users with simple tools that are robust yet efficient. These simple and efficient methods enable one to gain insight into the main features of flood propagation in river channels to avoid the numerical complexity of dynamic wave routing models. However, such simplified methods are limited in their application. Therefore, a more computationally efficient routing model is required that solves the complete Saint-Venant equations and also considers other sub-processes within the channel routing sub-routine such as transmission losses, evaporation losses and bank storage.

Routing of flood flows in meandering rivers with wide floodplains using a modified form of the Saint Venant equations was first proposed by Fread (1976). Using these original equations a new form of the momentum equation was derived in order to solve the Saint-Venant's equations for flood routing in prismatic open channels and floodplains with varying top-widths (Perdikaris, 2013). The simplified dynamic wave model was derived from the modified form of the Saint Venant Equations proposed by Fread, by assuming the derivative $\frac{\partial S f}{\partial x}$ to be negligible with respect to other terms of the momentum equation. Keskin and Agiralioglu (1997) and Perdikaris 
(2013), found this term to have less of an impact on the routing of flood flows then other terms in the momentum equation.

This methodology for deriving the momentum equation was first proposed by Keskin and Agiralioglu (1997). However, their formulation for solving the Saint Venant equations was limited to flood routing in rectangular open channels with constant top-widths. The numerical solution utilized in the current study expands upon their original formulations for solving the Saint Venant equations to include trapezoidal and triangular open channels. Expression of the channel reach and floodplain in terms of a prism was first proposed by McCarthy in 1938 and later presented by Perumal and Price (2013) and Reggiani et al., (2016) in the derivation of the fully mass conservative, variable parameter McCarthy-Muskingum (VPMM) method derived from the Saint Venant Equations.

In this formulation, the momentum equation transforms to a partial differential equation which has two parameters related to cross-sectional area and discharge for the channel, left floodplain and right floodplain. The simplified dynamic wave model is further extended to account for transmission losses, evaporation losses and bank storage along the length of the channel. The simplified dynamic model is solved using an explicit finite difference scheme that is backward in space and forward in time. In the computational procedure after computing the discharge from the momentum equation, the cross-sectional area is obtained from the continuity equation and subsequently the depth of flow is calculated using a modified form of the quadratic formula for a given location along the channel and floodplain.

In order to solve both the continuity and momentum equations the hydraulic parameters of the channel and floodplain are varied at every routing step along the reach. In doing so, one can model the non-linear behaviour of the flood wave propagation in the river (Perumal et. al., 2017). In the present study, the simplified dynamic wave model is applied and evaluated on a reach of the Credit River Watershed. The results are compared with the solutions of the full dynamic wave model, and the diffusion wave model.

\section{Method}

\subsection{Mathematical Formulations}

Floodplains are important for drainage and sustainment of connectivity with main stem river particularly during high-water stages (Rudorff et al., 2014). The modified forms of the Saint Venant Equations, according to (Fread, 1976) are as follows:

$$
\begin{gathered}
\frac{\partial\left(K_{c n} Q\right)}{\partial x_{c n}}+\frac{\partial\left(K_{l f} Q\right)}{\partial x_{l f}}+\frac{\partial\left(K_{r f} Q\right)}{\partial x_{r f}}+\frac{\partial\left(A_{c n}+A_{l f}+A_{r f}\right)}{\partial t}-q_{L 1}-q_{L 2}=0 \\
\frac{\partial Q}{\partial t}+\frac{\partial\left(\frac{K_{c n}^{2} Q^{2}}{A_{c n}}\right)}{\partial x_{c n}}+\frac{\partial\left(\frac{K_{l f}^{2} Q^{2}}{A_{l f}}\right)}{\partial x_{l f}}+\frac{\partial\left(\frac{K_{r f}^{2} Q^{2}}{A_{r f}}\right)}{\partial x_{r f}}+g A_{c n}\left(\frac{\partial y_{c n}}{\partial x_{c n}}+S_{f c n}-S_{o c n}\right)+g A_{l f}\left(\frac{\partial y_{l f}}{\partial x_{l f}}+S_{f l f}-S_{o l f}\right)+ \\
g A_{r f}\left(\frac{\partial y_{r f}}{\partial x_{r f}}+S_{f r f}-S_{o r f}\right)+M_{L 1}+M_{L 2}
\end{gathered}
$$

In equations 1 and 2, $x$ is the longitudinal distance along the channel (m), $Q$ is the total flow ( $\left.\mathrm{m}^{3} / \mathrm{s}\right), A$ is the wetted cross-sectional area of flow $\left(\mathrm{m}^{2}\right), t$ is the time (s), $y$ is the surface level of the water in the channel and floodplain, $g$ is the acceleration due to gravity $\left(9.81 \mathrm{~m} / \mathrm{s}^{2}\right), S_{o}$ is the bed slope and $S_{f}$ is the slope of the energy grade line. The parameters $q_{L 1}$ and $q_{L 2}$ in equation 1 represent the lateral inflows to the channel for surface flow and baseflow (interflow and shallow groundwater flow) respectively. The parameters $M_{L 1}$ and $M_{L 2}$ in equation 2 are the momentum effects of lateral inflows $q_{L 1}$ and $q_{L 2}$. The parameters $\left(K_{c n}, K_{l f}\right.$, and $\left.K r f\right)$ proportion the total flow $(Q)$ into the channel, left floodplain and right floodplain, respectively. These are defined (Fread, 1976) as follows:

$$
\begin{gathered}
K_{c n}=\frac{1}{\left(1+k_{l}+k_{r}\right)} \\
K_{l f}=\frac{k_{l}}{\left(1+k_{l}+k_{r}\right)}
\end{gathered}
$$




$$
\begin{aligned}
& K_{r f}=\frac{k_{r}}{\left(1+k_{l}+k_{r}\right)} \\
& k_{l}=\frac{Q_{l f}}{Q_{c n}}=\frac{n_{c n} A_{l f}}{n_{l f} A_{c n}}\left(\frac{R_{l f}}{R_{c n}}\right)^{2 / 3}\left(\frac{\Delta x_{c n}}{\Delta x_{l f}}\right)^{1 / 2} \\
& k_{r}=\frac{Q_{r f}}{Q_{c n}}=\frac{n_{c n} A_{r f}}{n_{r f} A_{c n}}\left(\frac{R_{r f}}{R_{c n}}\right)^{2 / 3}\left(\frac{\Delta x_{c n}}{\Delta x_{r f}}\right)^{1 / 2}
\end{aligned}
$$

Equations 4 and 5 represent the ratio of flow in the channel section to flow in the left and right floodplain sections; the flows are expressed in terms of the Manning equation, the energy slope approximated by the water surface slope $(\Delta x / \Delta y)$. Equations 1 and 2, along with Manning's friction formula can be solved algebraically according to Perdikaris (2013).

The governing equations for the simplified dynamic wave model are as follows:

$$
\frac{\partial Q}{\partial t}+\alpha_{c n} \frac{\partial Q}{\partial x_{c n}}+\alpha_{l f} \frac{\partial Q}{\partial x_{l f}}+\alpha_{r f} \frac{\partial Q}{\partial x_{r f}}+\beta_{c n}+\beta_{l f}+\beta_{r f}=0
$$

In which,

$$
\begin{gathered}
\alpha_{c n}=\frac{2 K_{c n}^{2} Q}{A_{c n}}+\frac{\frac{3}{5}\left(\frac{g A_{c n}}{B_{b n k}}-\frac{K_{c n}^{2} Q^{2}}{A_{c n}^{2}}\right)}{\frac{Q}{A_{c n}}} \\
\alpha_{l f}=2 \frac{K_{l f}^{2} Q}{A_{l f}}+\frac{\left(\frac{g A_{l f}}{B_{l f}}-\frac{K_{l f}^{2} Q^{2}}{A_{l f}^{2}}\right)}{\frac{Q}{A_{l f}}\left(\frac{5}{3}-\frac{2}{3} R_{l f} \frac{\sqrt{1+z_{l f}^{2}}}{B_{l f}}\right)} \\
\alpha_{r f}=2 \frac{K_{r f}^{2} Q}{A_{r f}}+\frac{\left(\frac{g A_{r f}}{B_{r f}}-\frac{K_{r f}^{2} Q^{2}}{A_{r f}^{2}}\right)}{\frac{Q}{A_{r f}}\left(\frac{5}{3}-\frac{2 A_{r f}}{3 P_{r f}} \sqrt{1+z_{r f}^{2}}\right)}
\end{gathered}
$$

And

$$
\begin{gathered}
\beta_{c n}=g A_{c n}\left(S_{f c n}-S_{o c n}\right)+M_{L 1}+M_{L 2} \\
\beta_{l f}=g A_{l f}\left(S_{f l f}-S_{o l f}\right) \\
\beta_{r f}=g A_{r f}\left(S_{f r f}-S_{o r f}\right)
\end{gathered}
$$

The subscripts $c_{n}, l_{f}$ and $r_{f}$ in equations 1 through 14 represent the channel, left floodplain and right floodplain components respectively. The friction slope terms in equations 12, 13 and 14, can be obtained from Manning's friction formula. The momentum equation in equation 2 is transformed into equation 8 . Equation 8 can be solved relatively easily by using a numerical solution subject to initial and boundary conditions.

The simplified dynamic wave model was further extended to include transmission losses along the stream. Transmission losses (gains) include evaporation, seepage, diversions and (return flow). The methodology presented here, is the same used in the SWAT model for accounting for transmission losses for a reach (Neitsch et al, 2005). Evaporation losses from the reach are calculated as follows (Neitsch et al, 2005):

$$
E_{i}=\operatorname{coef}_{e v} \cdot E_{o} \cdot L_{i} \cdot \bar{W} \cdot f r \Delta t
$$

Where $E_{i}$ is the evaporation from the reach $(i)$ for the time step $\left(\mathrm{m}^{3}\right)$, coefev $f_{e v}$ is an evaporation coefficient, $E_{o}$ is potential evaporation $(\mathrm{mm}), L_{i}$ is the reach length $(\mathrm{km}), \bar{W}$ is the average channel top width at cross-sections $i$ and at $i+l(\mathrm{~m})$, and $f r \Delta t$ is the fraction of the time step in which water is flowing in the reach. The fraction of the time step in which water is flowing in the reach is calculated by dividing the travel time by the length of the time step. 
Replacing the first two terms in Equation 4.140, with the amount of precipitation, $P C P_{o}(\mathrm{~mm})$ for the time step, one can determine the total volume of precipitation added to the reach during that time step. Seepage losses from the reach were estimated with the following equation (Neitsch et al, 2005):

$$
T_{\text {loss }, i}=K_{\text {eff }, i} \cdot T T_{i} \cdot P_{i} \cdot L_{i}
$$

Where $T_{\text {loss }, i}$ are the reach $(i)$ seepage losses $\left(\mathrm{m}^{3}\right), K_{\text {eff, } i}$ is the effective hydraulic conductivity of the reach $(\mathrm{mm} / \mathrm{hr})$, $T T_{i}$ is the flow travel time (hr), $P_{i}$ is the wetted perimeter (m), and $L_{i}$ is the reach length (km). Typical values of $K$ for various alluvium materials can range from $127 \mathrm{~mm} / \mathrm{hr}$ (clean gravel and large sand) to $0.025 \mathrm{~mm} / \mathrm{hr}$ (bed material with high silt clay content, Lane 1983). For perennial streams with continuous groundwater contribution, the effective hydraulic conductivity will be zero.

The amount of water entering bank storage on a given time step is calculated by using the following equation (Neitsch et al, 2005).

$$
b n k_{\text {in }}=T_{\text {loss }, i} \cdot\left(1-f r_{\text {trns }}\right)
$$

Where $b n k_{i n}$ is the amount of water entering bank storage $\left(\mathrm{m}^{3}\right), T_{\text {loss }, i}$ is the seepage loss $\left(\mathrm{m}^{3}\right)$, and $f r_{\text {trns }}$ is the fraction of seepage losses partitioned to the deep aquifer.

The volume of water entering the reach from bank storage is calculated as follows (Neitsch et al, 2005):

$$
V_{b n k}=b n k \cdot\left(1-\exp \left[-\alpha_{b n k}\right]\right)
$$

Where $V_{b n k}$ is the volume of water added to the reach via return flow from bank storage $\left(\mathrm{m}^{3}\right)$, bnk is the total amount of water within bank storage $\left(\mathrm{m}^{3}\right)$ and $\alpha_{b n k}$ is the bank flow recession constant or constant of proportionality.

Water storage within the reach at the end of the time step is calculated by using the following equation (Neitsch et al, 2005):

$$
\begin{aligned}
& V_{\text {stored }, f}=V_{\text {stored }, o}+V_{\text {in }}-V_{\text {out }}-T_{\text {loss }, i}-E_{i}+P C P_{i}+\operatorname{div}+V_{b n k} \\
& \text { depth }=\text { depth }_{\text {bankfull }}+\sqrt{\frac{\left(A-A_{\text {bankfull }}\right)}{z_{f l d}}+\left(\frac{W_{b t m, f l d}}{2 \cdot z_{f l d}}\right)^{2}}-\left(\frac{W_{b t m, f l d}}{2 \cdot z_{f l d}}\right)
\end{aligned}
$$

Where $V_{\text {stored } f}$ is the volume of water in the reach at the end of the time step $\left(\mathrm{m}^{3}\right), V_{\text {stored, } o}$ is the volume of water in the reach at the beginning of the time step $\left(\mathrm{m}^{3}\right), V_{\text {in }}$ is the volume of water flowing into the reach during the time step $\left(\mathrm{m}^{3}\right), V_{\text {out }}$ is the volume of water flowing out of the reach during the time step $\left(\mathrm{m}^{3}\right)$ and all other terms are as previously defined.

Equation 20 represents a modified form of the quadratic formula for solving the depth of flow. The depth is the depth of flow (m), depth bankfull is the depth of water in the channel when filled to the top of the bank (m), $A$ is the wetted cross-sectional area of flow in the channel and floodplain for a given depth of water $\left(\mathrm{m}^{2}\right), A_{\text {bankfull }}$ is the wetted cross-sectional area of flow in the channel when filled to the top of the bank $\left(\mathrm{m}^{2}\right), W_{b t m}$ ffd is the bottom width of the floodplain (m), and $z_{f l d}$ is the inverse of the floodplain side slope.

The model treats the volume of outflow $\left(V_{\text {out }}\right)$ as the net amount of water removed from the reach. As transmission losses, evaporation and other water losses for the reach segment are calculated, the amount of outflow to the next amount will equal the value obtained from equation 19. The total volume within the channel is estimated by summing all of the individual reach segment volumes within the channel. The average wetted cross-sectional area $(A)$ of flow for each reach segment along the channel is calculated by dividing the volume of the reach segment by the longitudinal distance $\Delta x$ of the reach segment. The depth of flow for each reach segment is then calculated using equation 20. Equations 15 thru 19 are solved periodically by incorporating a variable time step. The flow routing equations and equation 20 are solved using a computational time step $(\Delta t)$ of minutes and/or seconds and transmission loss equations, are solved using a time step $(\Delta t)$ of days, thereby, ensuring the computational efficiency of the equations.

Equation 1 and equations 8 thru 14 are solved using an explicit finite difference solution that is backward in space and forward in time.

$$
Q_{i}^{j+1}=Q_{i}^{j}-\left(Q_{i}^{j}-Q_{i-1}^{j}\right)\left(\alpha_{i c n}^{j} \frac{\Delta t}{\Delta x_{c n}}+\alpha_{i l f}^{j} \frac{\Delta t}{\Delta x_{l f}}+\alpha_{i r f}^{j} \frac{\Delta t}{\Delta x_{r f}}\right)-\Delta t\left(\beta_{i c n}^{j}+\beta_{i l f}^{j}+\beta_{i r f}^{j}\right)
$$




$$
\begin{gathered}
A_{i}^{j+1}=A_{i}^{j}-\left(Q_{i}^{j+1}-Q_{i-1}^{j+1}\right) \Delta t\left(\frac{K_{c n}}{\Delta x_{c n}}+\frac{K_{l f}}{\Delta x_{l f}}+\frac{K_{r f}}{\Delta x_{r f}}\right)+\Delta t\left(q_{L 1}+q_{L 2}\right) \\
A_{i c n}^{j+1}=K_{c n} A_{i}^{j+1} \\
A_{i l f}^{j+1}=K_{l f} A_{i}^{j+1} \\
A_{i r f}^{j+1}=K_{r f} A_{i}^{j+1} \\
Q_{i c n}^{j+1}=K_{c n} Q_{i}^{j+1} \\
Q_{i l f}^{j+1}=K_{l f} Q_{i}^{j+1} \\
Q_{i r f}^{j+1}=K_{r f} Q_{i}^{j+1}
\end{gathered}
$$

Where

$$
\begin{aligned}
& \alpha_{i_{c n}}^{j}=\frac{2 K_{c n}^{2} Q_{i}^{j}}{A_{i c n}{ }^{j}}+\frac{\frac{3}{5}\left(\frac{g A_{i c n}{ }^{j}}{B_{b n k}}-\frac{K_{c n}^{2} Q_{i}^{j^{2}}}{A_{i_{c n}}^{j^{2}}}\right)}{\frac{Q_{i}^{j}}{A_{i c n}{ }^{j}}} \\
& \alpha_{i_{l f}}^{j}=2 \frac{K_{l f}^{2} Q_{i}^{j}}{A_{i_{l f}}^{j}}+\frac{\left(\frac{g A_{i_{l f}}^{j}}{B_{i l f}^{j}}-\frac{K_{l f}^{2} Q_{i}^{j^{2}}}{A_{l f}^{2}}\right)}{\frac{Q_{i}^{j}}{A_{i l f}^{j}}\left(\frac{5}{3}-\frac{2}{3} R_{i}^{j} \frac{\sqrt{1+z_{l f}^{2}}}{B_{i_{l f}}^{j}}\right)} \\
& \alpha_{i r f}^{j}=2 \frac{K_{r f}^{2} Q_{i}^{j}}{A_{i_{r f}}^{j}}+\frac{\left(\frac{g A_{i_{r f}}^{j}}{B_{i_{r f}}^{j}}-\frac{K_{r f}^{2} Q_{i}^{j^{2}}}{A_{i_{r f}}^{j^{2}}}\right)}{\left.\frac{Q_{i}^{j}\left(\frac{5}{3}-\frac{2}{A_{i_{r f}}^{j} \sqrt{1+z_{r f}^{2}}}\right)}{A_{P_{i r f}^{j}}^{j} B_{i_{r f}}^{j}}\right)} \\
& \beta_{i_{c n}}^{j}=g A_{i_{c n}}^{j}\left(S_{f c n_{i}^{j}}^{j}-S_{o c n}\right)+M_{L 1}+M_{L 2} \\
& \beta_{i_{l f}}^{j}=g A_{i_{l f}}^{j}\left(S_{f l f_{i}^{j}}^{j}-S_{o l f}\right) \\
& \beta_{i r f}^{j}=g A_{r f_{i}^{j}}^{j}\left(S_{f r f_{i}^{j}}^{j}-S_{\text {orf }}\right)
\end{aligned}
$$


Given the relative computational simplicity of the simplified dynamic wave model the equations can be easily programmed into a spreadsheet. Equations 21 thru 34 were programmed into an Excel spreadsheet along with equations 15 through 20. Equations (21-34) and (15-20) represents a column in the spreadsheet for each section $(i)$ along a reach and/or sub-reach. In addition, each time step $\left(\Delta t_{j}\right)$ is represented by a row in the spreadsheet. The order in which the equations are solved is as follows: equations 21 to 28, equation 20, wetter perimeter $P_{i}$, hydraulic radius $R_{i}$, slope of the energy grade line $S_{f i}$, equations 29 to 34 and equations 15-19 and equation 20. The slope of the energy grade line $S_{f i}$ is solved using Manning's friction formula.

\subsection{Application of the Simplified Dynamic Wave Model to the Credit River}

The performance of the simplified dynamic wave model on recorded hydrographs is evaluated for a reach along the Credit River. The Credit River Watershed is a mid-sized watershed situated in Southern Ontario, Canada (total drainage area is approximately $1000 \mathrm{~km}^{2}$ ). The Credit River watershed contains 22 subwatersheds with over 1500 $\mathrm{km}$ of streams and creeks. This watershed was selected to evaluate the performance of the simplified dynamic wave model because there is a very extensive data set available for the watershed on hydrometeorological measurements, the channel and floodplain characteristics of the river reaches are well defined, and previous studies on flooding along the Credit River watershed have been completed and are documented. The performance of the simplified dynamic wave model was compared to the diffusion wave model and the more complex full dynamic wave model. The purpose of comparing the simplified dynamic wave model to the diffusion wave model and the full dynamic wave model was not to determine if the simplified dynamic wave model performed better than the latter, but to benchmark the model in relation to its performance to the latter. Since the diffusion wave model and the dynamic wave model are both accepted methods for flood routing.

A typical water year in Southern Ontario is between November $1^{\text {st }}$ and October $31^{\text {st }}$ of the following year. Water levels along the Credit River are typically at normal levels during the mid to late fall period; with average antecedent conditions. Management of the watershed is the responsibility of the Credit Valley Conservation Authority (CVC). Monitoring of streamflow and water levels is a shared responsibility between the Federal and Provincial Governments and the CVC. In total there are 9 Federal Water Survey of Canada (WSC) streamflow gauging stations along the Credit River and 7 streamflow gauging stations that are maintained and operated by CVC. Figure 1 illustrates the location of the, the major flow paths along the Credit River, the 9 WSC streamflow gauging stations (indicated by a red target) and the $7 \mathrm{CVC}$ streamflow gauging stations (indicated by a blue diamond) along the Credit River Watershed.

The study reach, is located along the mid-portion of the watershed. It extends from Cheltenham to Norval and is approximately $23 \mathrm{~km}$ in length with an average channel bed slope of $0.0023 \mathrm{~m} / \mathrm{m}$, and a Manning's ' $n$ ' value of 0.040 for the channel section. This portion of the watershed is dominated by both the Niagara Escarpment and the Oak Ridges Moraine, two prominent physiographic features within the Credit River watershed. This reach along the mid-potion of the Credit River is characterized by exposed rocks and steep cliffs due to the presence of the Niagara Escarpment Resulting in 'quick' discharge releases to the main channel through subsurface and shallow groundwater flow. However, the presence of trees and woodlots along the edge of the escarpment has slowed this process down significantly (Credit Valley Conservation, 1990). The bed of the main channel is made up of both sand and gravel; as a result, a portion of the flow is lost to the deep groundwater aquifer along this reach. Streamflow data for routing the flows along this reach of the Credit River was obtained from WSC. Flow data in 15-minute intervals was obtained for the following stations: Boston Mills (02HB018), Silver Creek (02HB008) and Norval (02HB025), for the period January 1, 1998 to December 31, 2005.

The study reach was subdivided into 7 sub-reaches. The first two sub-reaches were characterized as triangular shapes with a side slope of 10:1 (H:V). The subsequent sub-reaches were characterized as a trapezoidal section with a bottom width of $24 \mathrm{~m}$ and a side slope of $2: 1(\mathrm{H}: \mathrm{V})$. These characterizations were based on field surveyed cross-sections for each sub-reach. Each sub-reach was further subdivided into 11 sub-reaches to maintain computational stability and ensure convergence of the numerical solution, $\Delta x=324,384,180,653,111,477$ and $144 \mathrm{~m}$ for sub-reaches $1,2,3,4,5,6$ and 7 respectively. In addition, $\Delta t$ values were set equal to $20 \mathrm{~s}, 20 \mathrm{~s}, 20 \mathrm{~s}$, $20 \mathrm{~s}, 15 \mathrm{~s}, 12 \mathrm{~s}$ and $9 \mathrm{~s}$ for sub-reaches $1,2,3,4,5,6$ and 7 respectively to maintain computational stability and to satisfy the courant condition. For the floodplain component, the side slope for the floodplain was set to 4:1 (H: V), for all sub-reaches.

The Manning's " $n$ " value was set equal to 0.033 for the channel potion and 0.08 for the floodplain potion for each reach. The Manning's " $n$ " values were obtained from the routing reaches of the calibrated Guelph All-Weather Sequential Events Runoff (GAWSER) model for the Credit River watershed that was developed as part of the Adaptive Water Management Strategy for the Credit River (Credit Valley Conservation, 2002). 
For the simplified dynamic wave model, to account for seepage losses along the reach, the hydraulic conductivity of the reach $(K)$ was set equal to $6 \mathrm{~mm} / \mathrm{h}$ (Credit Valley Conservation, 2007). The fraction of seepage losses partitioned to the deep aquifer $\left(f r_{t r n s}\right)$ was set equal to 1.0, since all seepage losses along this reach occur through the bed of the river and are partitioned to the deep aquifer (Credit Valley Conservation, 2007). The bank flow recession constant $(\alpha)$ was set equal to zero, since there was no return flow to bank storage $\left(f f_{\text {trrs }}=1.0\right)$ and a time series of recorded hydrographs from Credit Valley Conservation stream gauge stations (CVC stream gauge at Cheltenham and CVC stream gauge at Main Street) was used to account for lateral seepage inflows along the reach.

The upstream boundary condition was defined by the inflow hydrograph time series from Water Survey of Canada's at the Boston Mills gauge station (station no. 02HB018, Figure 1). The downstream boundary condition was defined by the measured rating curve from Water Survey of Canada's Norval gauge station (station no. 02HB025, Figure 1). Lateral inflow near the outlet at Norval was quantified by the inflow hydrograph time series from Water Survey of Canada's Silver Creek gauge station (station no. 02HB008, Figure 1).

The study reach was subdivided into 7 sub-reaches. The first two sub-reaches were characterized as triangular shapes with a side slope of 10:1 (H:V). The subsequent sub-reaches were characterized as a trapezoidal section with a bottom width of $24 \mathrm{~m}$ and a side slope of $2: 1(\mathrm{H}: \mathrm{V})$. These characterizations were based on field surveyed cross-sections for each sub-reach. Each sub-reach was further subdivided into 11 sub-reaches to maintain computational stability and ensure convergence of the numerical solution, $\Delta x=324,384,180,653,111,477$ and $144 \mathrm{~m}$ for sub-reaches $1,2,3,4,5,6$ and 7 respectively. In addition, $\Delta t$ values were set equal to $20 \mathrm{~s}, 20 \mathrm{~s}, 20 \mathrm{~s}$, $20 \mathrm{~s}, 15 \mathrm{~s}, 12 \mathrm{~s}$ and $9 \mathrm{~s}$ for sub-reaches $1,2,3,4,5,6$ and 7 respectively to maintain computational stability and to satisfy the courant condition. For the floodplain component, the side slope for the floodplain was set to 4:1 (H: V), for all sub-reaches.

The Manning's " $n$ " value was set equal to 0.033 for the channel potion and 0.08 for the floodplain potion for each reach. The Manning's " $n$ " values were obtained from the routing reaches of the calibrated Guelph All-Weather Sequential Events Runoff (GAWSER) model for the Credit River watershed that was developed as part of the Adaptive Water Management Strategy for the Credit River (Credit Valley Conservation, 2002).

For the simplified dynamic wave model, to account for seepage losses along the reach, the hydraulic conductivity of the reach $(K)$ was set equal to $6 \mathrm{~mm} / \mathrm{h}$ (Credit Valley Conservation, 2007). The fraction of seepage losses partitioned to the deep aquifer $\left(f r_{\text {trns }}\right)$ was set equal to 1.0, since all seepage losses along this reach occur through the bed of the river and are partitioned to the deep aquifer (Credit Valley Conservation, 2007). The bank flow recession constant $(\alpha)$ was set equal to zero, since there was no return flow to bank storage $\left(f f_{\text {trrs }}=1.0\right)$ and a time series of recorded hydrographs from Credit Valley Conservation stream gauge stations (CVC stream gauge at Cheltenham and CVC stream gauge at Main Street) was used to account for lateral seepage inflows along the reach.

The upstream boundary condition was defined by the inflow hydrograph time series from Water Survey of Canada's at the Boston Mills gauge station (station no. 02HB018, Figure 1). The downstream boundary condition was defined by the measured rating curve from Water Survey of Canada's Norval gauge station (station no. 02HB025, Figure 1). Lateral inflow near the outlet at Norval was quantified by the inflow hydrograph time series from Water Survey of Canada's Silver Creek gauge station (station no. 02HB008, Figure 1).

The FLDWAV modelling application was used to set-up both the diffusion wave and full dynamic wave routing models. The FLDWAV modelling application was selected because it contains both flood routing models. FLDWAV uses a weighted four-point implicit finite difference scheme to solve the expanded Saint Venant Equations (full dynamic wave) and simplified diffusion wave model. The same data set and modelling set-up was used to develop the diffusion wave model and full dynamic wave model for this reach of the Credit River. 


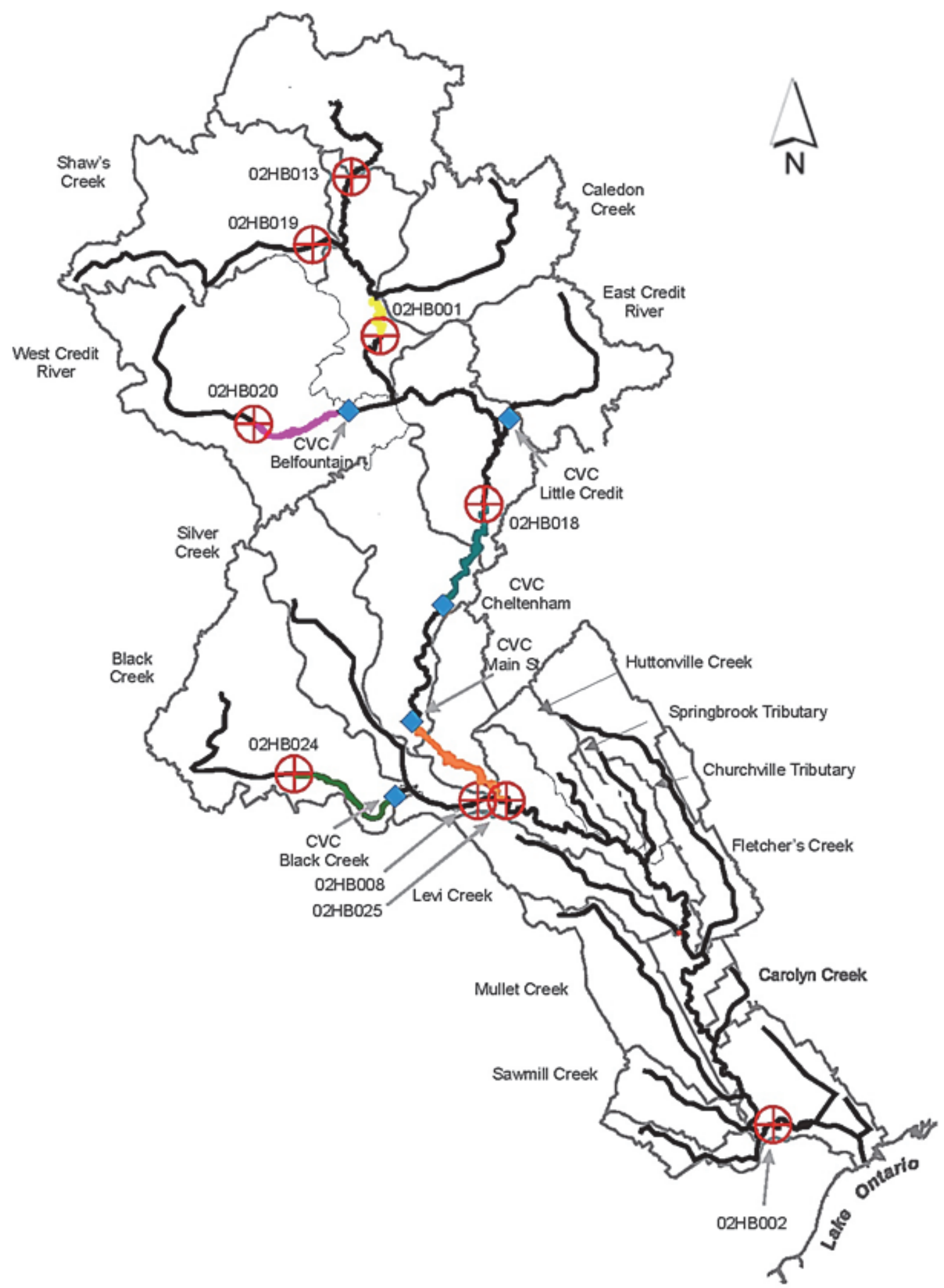

Figure 1. Credit River Watershed, flow paths, subwatersheds, Water Survey of Canada stream gauge stations and Credit Valley Conservation stream gauge stations

The assumptions used to represent a hydraulic phenomenon into mathematical relationships (or models) inevitably results in some degree of inaccuracy. Some errors (inaccuracies) also occur for approximating a differential equation (mathematical equation) by finite differences. Truncation errors also occur in the numerical solution 
technique. Therefore, it is generally accepted that no single simulation model output will be identical in all respects to the physical phenomenon it aims to represent. However, it is required that this output be sufficiently close to its physical counterpart for the model simulation to be considered acceptable. The principle of goodness-of-fit is a measure of the degree to which the output conforms to the corresponding observed data. Goodness-of-fit techniques may range from purely subjective graphical (visual) methods to purely objective using statistical methods. These relationships usually portray the difference between the simulated and observed variables. Prior to any calibration or model application, the user should establish criteria for comparison. However, if too many criteria are used and are frequently switched, the assessment of the model performance becomes difficult.

Related to model simulation assessment is the graphical method of evaluation, plotting the observed and simulated hydrographs on the same graph. A visual comparison is then made of peak flows and hydrograph shapes. The importance of the graphical method should not be overlooked. Although it is usually thought to be highly subjective and difficult when comparing the performance of similar models, it provides a general appreciation of the model's capabilities. However, it may be misleading in some cases when a visual check is made for the rising and recession parts of the hydrograph. A visual check may appear to have an excellent fit, but the actual relative error at a particular point might be high. In these instances the user can only resort to statistical goodness-of-fit techniques.

A statistical approach was followed to evaluate the performance of the three routing models. The main objective was to examine the closeness of simulated output more with the observed output by minimizing the objective function. In general, different goodness-of-fit criteria are weighted in favour of different hydrograph components, and may give more weight to a certain aspect of disagreement between observed and simulated results. Thus, there is no general criterion, and the one ultimately selected should depend on the objective of the modelling exercise (Chatila, 1992). The calibration and validation procedure along with the statistical criteria used to evaluate the performance of the different routing methods are described in the proceeding section.

The evaluation of a model's behaviour and performance is commonly made and reported through comparisons of simulated and observed variables. Single and multi-response, efficiency criteria are commonly used by hydrologists to provide an objective assessment of the "closeness" of the simulated behaviour to the observed measurements (Beven, 2001). While there are a few efficiency criteria such as the Nash-Sutcliffe efficiency, coefficient of determination, and index of agreement that are frequently used in hydrologic and hydraulic modeling studies and reported in the literature, there are a large number of other efficiency criteria to choose from. Each criterion may place different emphasis on different types of simulated and observed behaviours. The selection of the best efficiency measures should reflect the intended use of the model and should concern model quantities which are deemed relevant for the study at hand (Janssen and Heuberger 1995). Krause et al, (2005), recommends using a combination of different efficiency criteria complemented by the assessment of the absolute or relative error. The goal should be to provide good values for a set of measures, even if they are lower than single best realizations, to include the whole dynamics of the model results (Krause et al., 2005).

The calibration procedure adopted for calibrating the different routing models was a systematic approach to manual calibration. The systematic manual calibration relied on the measured and estimated values of the model parameters (Manning's ' $n$ ' value) available from Credit Valley Conservation Authority. This ensured that a physically - meaningful set of initial parameters (Manning's ' $n$ ' value) was used for the calibration. In the next step, a calibration scheme was defined, which systematically changed the value of a given parameter (Manning's ' $n$ ' value) while keeping the remaining parameters constant. A $10 \%$ increase and/or decrease step was used to linearly change parameter values until the soft limits were reached. The soft limits were defined as the $25 \%-175 \%$ of the initial parameter value (initial $\pm 75 \%$ ), which encompassed all reasonably expected values.

For the purposes of model testing and evaluation the following tools and criteria were used to test and evaluate the performance of the different routing models: comparison graph between simulated and observed measurements and statistical goodness-of-fit measurements. The comparison graph between simulated and observed measurements provides a plot of the observed and simulated output of variables at a specified location. For the reach between Melville and Cataract comparisons were made between the observed and simulated streamflows at the Cataract gauge station (Water Survey of Canada station, 02HB001). For the reach between Boston Mills and Norval comparisons were made between the observed and simulated streamflows at the Norval gauge station (Water Survey of Canada station, 02HB025).

A comprehensive summary of statistical performance measures used for the evaluation of the different routing models are provided in the literature by Sorooshian et al. (1983); American Society of Civil Engineers (1993); Gupta and Sorooshian (1998); and Moriasi et al. (2007). For the purposes of this study, five (5) different statistical goodness-of-fit measures were used to evaluate the performance of the simplified dynamic model. These statistical 
goodness-of-fit measures included the coefficient of determination $(D)$; modified coefficient of efficiency $\left(E_{1}\right)$; root mean square error (RMSE); relative bias (RBIAS); and percent difference in runoff volumes $(\% V V l)$. When testing the performance of a model a combination of graphical techniques and statistical indices should be used for model evaluation (Moriasi, 2007).

Model validation is a process of testing the model's ability to simulate observed data other than those used for the calibration, with acceptable accuracy. During this process, calibrated model parameters are not subject to change and their values are kept constant during the simulation process. For the validation procedure in this study, the Manning's " $n$ " values for the different routing models were kept constant. The validation output for the different simulation events was assessed by flow comparison graphs and the statistical goodness-of-fit measures described above.

\section{Results and Discussions}

For the study reach, the diffusion wave, general dynamic wave and simplified dynamic wave models were used to simulate the time series flows at Norval for following calibration and validation events; May $12^{\text {th }}, 2000$ and August $19^{\text {th }}, 2005$. Through the calibration procedure the Manning's ' $n$ ' value for all three models was determined to be 0.033 for the channel portion and 0.100 for the floodplain portion. The channel and floodplain surface roughness along this reach is relatively uniform. Figure 2, compares the outflows hydrographs for the three different models with the observed hydrograph for the Norval gauge.

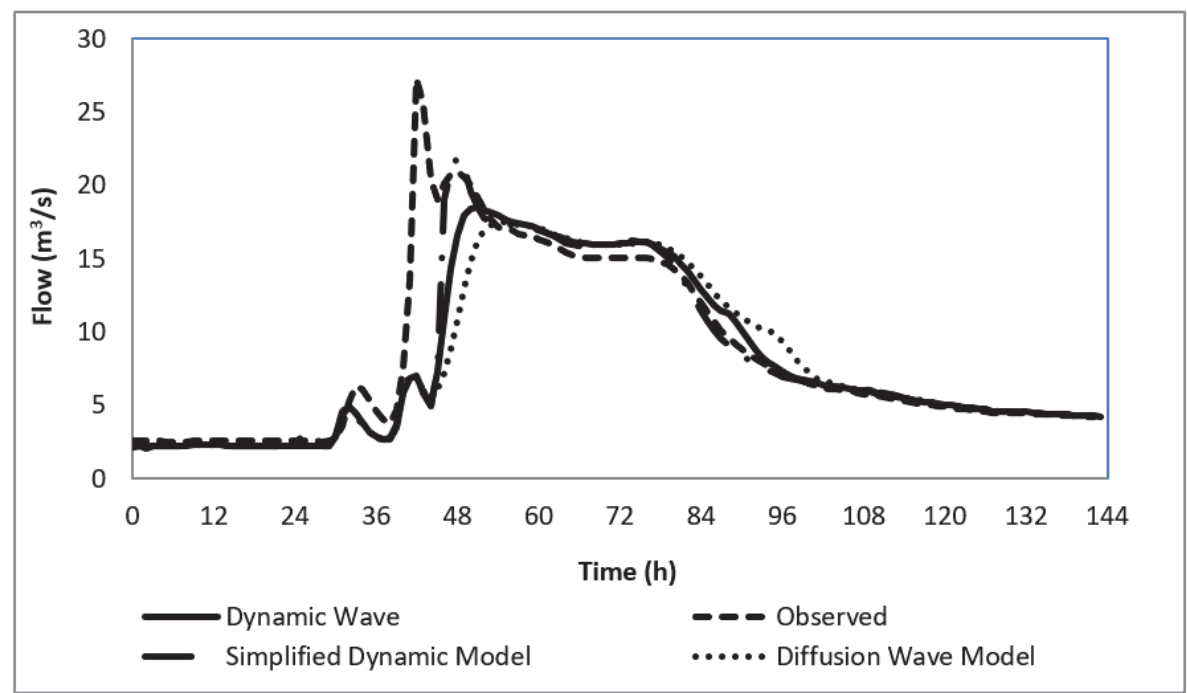

Figure 2. Comparison of outflow hydrographs for the diffusion wave, dynamic wave and simplified dynamic wave models and the observed hydrograph at the Norval stream gauge for the August $19^{\text {th }}, 2005$ event

Table 1 lists the statistical results for the validation event for each model. According to Figure 2, as expected, there is little difference between the outflow hydrographs for the diffusion wave model and the general dynamic wave model.

Table 1. Statistical quantities of coefficient of determination $\left(\mathrm{R}^{2}\right)$, modified coefficient of efficiency $\left(\mathrm{E}_{1}\right)$, root mean square error (RMSE), percent difference in volumes (\%VOL) and relative bias (RBIAS) for the August $19^{\text {th }}$, 2005 event for the three (3) different routing models for the study reach between Boston Mills and Norval

\begin{tabular}{llllll}
\hline Routing Models & $\mathrm{R}^{2}$ & $\mathrm{E}_{1}$ & $\mathrm{RMSE}$ & $\mathrm{VOL} \%$ & RBIAS \\
\hline Dynamic Wave & 0.74 & 0.78 & 3.2 & -6.4 & -4.7 \\
Diffusion Wave & 0.66 & 0.71 & 3.6 & -6.8 & -3.5 \\
Simplified Dynamic Wave & 0.80 & 0.82 & 3.0 & -6.4 & -5.4 \\
\hline
\end{tabular}

However, according to Table 1, the general dynamic wave model performed better than the diffusion wave model, with fair to good agreement between the observed and simulated outflow hydrographs for the general dynamic wave model and fair agreement for the diffusion wave model. According to Table 1, there was also good agreement between observed and simulated outflow hydrographs for the simplified dynamic wave model, whose performance 
was better than the general dynamic wave and diffusion wave models. This is expected, since the reach between Boston Mills and Norval is characterized as a cascade type, a sequence of discrete channel segments, with quick discharge characteristics, and the simplified dynamic wave model is referred to as a dynamic cascade. In some instances, the flow along this reach can become supercritical. The numerical solution used in the simplified dynamic model is a simple one of a cascade type. This type of model becomes particularly useful if the flow is supercritical or when the effect of the secondary boundary condition is negligible at the downstream end of the channel for subcritical flows.

A comparison was undertaken between the observed outflow hydrograph and the outflow hydrographs for the simplified dynamic model with transmission losses and without transmission losses; the results are illustrated in Figure 3. The differences in the discharge values between the two modelling scenarios are negligible. This is expected since, channel processes such as transmission losses, evaporation losses and precipitation gains tend to be negligible under high flow conditions (Philipp and Grundman, 2013).

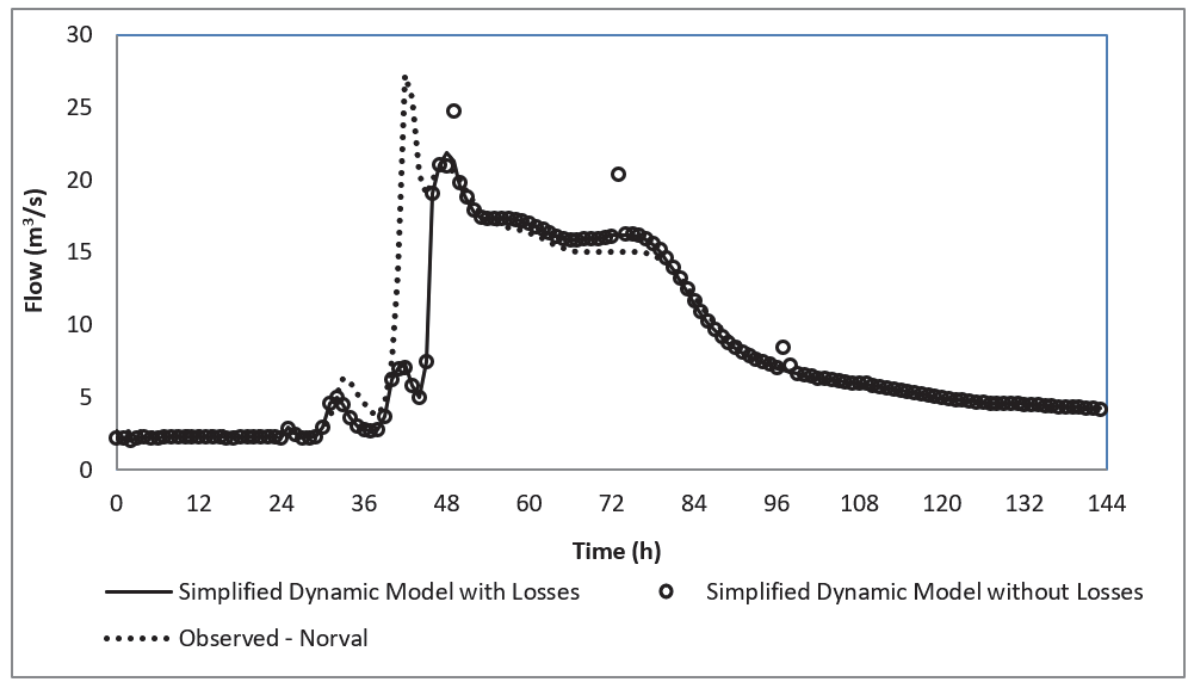

Figure 3. Comparison of outflow hydrographs for the simplified dynamic wave model with and without losses and the observed hydrograph at the Norval stream gauge for the August $19^{\text {th }}, 2005$ event

The simulated results and the statistical analysis indicate that the results of the simplified dynamic model are better if not more accurate than the results of the general dynamic wave and diffusion wave models. In addition, the simplified dynamic wave model could be used in some routing reaches where the full dynamic wave and diffusion wave models may not be appropriate. When compared to the full dynamic wave model, the simplified dynamic model is much easier to formulate than the dynamic wave model and is simple to calculate in comparison to the latter. This is an important point particularly in applications where computational efficiency is an issue such as the coupling of a hydrologic model and a global circulation model (Reggiani et al., 2014). When compared to the diffusion wave model the results show that the simplified dynamic wave model generates a smaller peak flow and time-to-peak than the diffusion wave model. Attenuation obtained by the simplified dynamic wave model depends on the characteristics of the inflow hydrograph including shape and peak discharge. Similar results were observed by Hasavand et al., (2013), which identified that for the shape of the upstream hydrograph, the relative error of a flat hydrograph was less compared with a rather sharp hydrographs, with steep rising and falling limbs. Indicating that the simplified dynamic wave model can be applied to cases or routing problems where neither the diffusion wave nor dynamic wave models are applicable.

\section{Conclusions}

The equations listed in this study can be applied to prismatic channel and floodplain sections with varying top widths. In was assumed that the longitudinal slope of the energy grade line is negligible with respect to the other terms in the Saint Venant equations. For this particular reach of the Credit River, it was shown that the simplified dynamic wave model performed better than both the diffusion wave and general dynamic wave models.

The results show that the simplified dynamic model generates a smaller peak flow and time-to-peak flow than the diffusion wave model. The attenuation obtained by the simplified dynamic wave model depends on the characteristics of the inflow hydrograph including shape and peak discharge, while in the latter this is not the case. 
The simplified dynamic model was also compared with the full dynamic wave model. Findings indicated that both models yield approximately the same characteristics of outflow hydrographs under the same conditions. However, the simplified dynamic wave model is much easier to formulate than the more complex full dynamic wave model and is much simpler to calculate in comparison to the latter, since it can be easily programmed into a spreadsheet.

The major advantages of the simplified dynamic wave model is that it can be applied to ungauged basins with unknown channel geometries; it requires a short execution time; and it captures the most relevant features of a dynamic wave such as the steepening of the rising limb of the hydrograph. In addition, the simplified dynamic wave computes the water levels for a reach at each routing step, a parameter that is essential in evaluating the flood risk in forecasting operations. For reasons of computational efficiency the simplified dynamic wave model is also appropriate for applications where computational effort becomes an issue. Furthermore, because of its computational simplicity, the model can also be used to check the computations of more complex routing models/algorithms, a requirement for all hydrologic/hydraulic modelling engineering problems within Ontario, Canada.

\section{Acknowledgments}

The authors would like to thank the Credit Valley Conservation Authority (CVC), Ministry of Natural Resources and Forestry (MNRF), Environment Canada and Climate Change (EC), Water Survey of Canada (WSC), and the Natural Science and Engineering Research Council of Canada (NSERC) for their funding, data and in-kind support of the study.

\section{References}

Akan, A. O., \& Yen, C. Y. (1981). Diffusion-wave flood routing in channel Networks. Journal of Hydraulics Division, ASCE, 107 (HY6 August), 719-732.

American Society of Civil Engineers (1973). Consumptive use of water irrigation water requirements. In M. E. Jensen (Ed.), Technical Committee on Irrigation Water Requirements, New York, 1973.

Beven, J. K. (2001). Rainfall-Runoff Modelling - The Primer, John Wiley \& Sons Ltd., Chichester, 319, 2001.

Brown, D. M., McKay, G. A., \& Chapman, L. J. (1974). The Climate of Southern Ontario. Climatological Studies Number 5, Environment Canada, Atmospheric Environment Services, En57-7/5.

Credit Valley Conservation. (1990). Credit River Water Management Strategy. Final Report, Meadowvale, Ontario.

Credit Valley Conservation. (2002). Credit River Adaptive Water Management Strategy. Final Report, Meadowvale, Ontario.

Credit Valley Conservation. (2007). Subwatershed 13: Phase I Characterization Report. Final Report, Meadowvale, Ontario.

De Saint, V. S., \& Barre, A. J. C. (1871). Théorie du mouvement non-permanent des Eaux avec Application aux crues des Rivieres et a l'introduction des Mareées dans leur lit, (Theory of Unsteady Water Flow, with Application to River Floods and to Propagation of Tides in River Channels), Comptes Rendus, 73, Academy Science, Paris: 148-154, 237-240.

Fread, D. L. (1976). Flood routing in meandering rivers with floodplains". In Symposium on Inland Waterways for Navigation, Flood Control and Water Division, I, ASCE, 16-35.

Fread, D. L. (1983). Applicability Criteria for Kinematic and Diffusion Routing Models. HRL-176, Hydrologic Research Laboratory, National Weather Service, Silver Spring, Md., 1983.

Fread, D. L. (1993). Flood runoff. Handbook of hydrology. In D. R. Maidment, (ed.), Chap. 9, McGraw-Hill, New York, 10.1-10.36.

Fread, D. L., \& Lewis, J. M. (1988). NWS FLDWAV Model: Theoretical Description and User Documentation, National Weather Service, Hydrologic Research Laboratory, Office of Hydrology, Novembe (28), 1998.

Gupta, H. V., Sorooshian, S., \& Yapo, P.O. (1998). Toward improved calibration of hydrologic models: Multiple and non commensurate measures of information. Water Resources Research, 34(4), 751-763.

Hasanvand, K., Hashemi, M. R., \& Abedini, M. J. (2013). Development of an Accurate Time Integration Technique for the Assessment of Q-Based versus h-Based Formulations of the Diffusion Wave Equation for Flow Routing. Journal of Hydraulic Engineering, 139(10), 1079-1088.

Janssen, P. H. M., \& Heuberger, P. S. C. (1995). Calibration of process oriented models. Ecological Modelling, 83, 55-66. 
Keskin, M. E. (1994). Investigation of flood routing by a dynamic model with dependent variable parameters. Ph.D. Dissertation, Civil Engineering Department Technical University of Istanbul.

Keskin, M. E., \& Agiralioglu, N. A. (1997). Simplified Dynamic Model for Flood Routing in Rectangular Channels. Journal of Hydrology, 202, 302-314.

Kibler, D. F., \& Woolhiser, D. A. (1970). The kinematic cascade as a hydrologic model. Colorado State University Hydrology Papers, 39, 27.

Kouwen, N. (1984). Flood Routing Sensitivity Study, Final Report, Project No. 111-11-02, Waterloo Research Institute, University of Waterloo, Waterloo, ON.

Krause, P., \& Flügel, W. A. (2005). Integrated research on the hydrological process dynamics from the Wilde Gera catchment in Germany; Headwater Control VI: Hydrology, Ecology and Water Resources in Headwaters, IAHS Conference, Bergen 2005.

Moin, S. M. A., \& Shaw, M. A. (1985). Regional Flood Frequency Analysis for Ontario Streams, Volume 1: Single Station Analysis and Index Method. A study funded under the Canada/Ontario Flood Damage Reduction Program.

Moriasi, et al. (2007). Model evaluation guidelines for systematic quantification of accuracy in watershed simulations. American Society of Agricultural and Biological Engineers, 50(3), 885-900.

Morris, H. M., \& Wiggert, J. M. (1972). Applied Hydraulics in Engineering, Ronald Press, New York, 1972.

Neitsch, S. L., Arnold, J. G., Kiniry, J. R., King, K. W., \& Williams, J. R. (2005). Soil and Water Assessment Tool (SWAT) theoretical documentation. Blackland Research Center, Texas Agricultural Experiment Station, Temple, Texas, BRC Report 02-05.

Perdikaris, J. (2013). Guelph Flood Forecasting Model (GFLOOD): An Innovative Modelling Approach to Estimating Flows and Water Levels in Streams". Ph.D. Dissertation, School of Engineering University of Guelph.

Perdikaris, J., Gharabaghi, B., \& McBean, E. (2011). A Methodology for Undertaking Vulnerability Assessments of Flood Susceptible Communities. International Journal of Safety and Security Engineering, 1(2), 126-146, https://doi.org/10.2495/SAFE-V1-N2-126-146.

Perumal, M., \& Price, R. K. (2013). A fully mass conservative variable parameter McCarthy-Muskingum method: Theory and verification, Journal of Hydrology, 502, 89-102.

Perumal, M., Gokmen, T., Madhusudana, C. R., \& Gurhan, G. (2017). Evaluation of a physically based quasilinear and a conceptually based nonlinear Muskingum methods, Journal of Hydrology, 546, 437-449.

Philipp, A., \& Grundmann, J. (2013). Integrated Modeling System for Flash Flood Routing in Ephemeral Rivers under the Influence of Groundwater Recharge Dams, Journal of Hydraulic Engineering, (12), 1234-1246.

Ponce, V. M., Li, R. M., \& Simons, D. B. (1978). Applicability of the kinematic and diffusion models, Journal Hydraulics Division, ASCE, 104(HY3 March), 353-360.

Reggiani, P., Todini, E., \& Meißner, D. (2016). On mass and momentum conservation in the variable-parameter Muskingum method, Journal of Hydrology, 543, 562-576.

Reggiani, P., Todini, E., \& Meißner, D. (2014). A conservative flow routing formulation: Déjà vu and the variableparameter Muskingum method revisited. Journal of Hydrology, 519, 1506-1515.

Rudorff, C. M., Melack, J. M., \& Bates, P. D. (2014). Flooding dynamics on the lower Amazon floodplain: 1. Hydraulic controls on water elevation, inundation extent, and river-floodplain Discharge, Water Resources Research, 50, 618-634.

Schroeter, H. O. (1999). Caledon Creek \& Credit River Subwatershed Study (Subwatersheds 16 and 18): Technical Appendix - Hydrology. Submitted to Credit Valley Conservation, Meadowvale, Ontario.

Singer, S. et al. (1994). Groundwater resources of the Credit River Watershed. Ministry of the Environment and Energy, Environmental Monitoring and Reporting Branch, Toronto, Ontario.

Sinha, J., Eswaran, J. S., \& Bhallamudi, S. M. (1995). Comparison of spectral and finite difference methods for flood routing, Journal of Hydraulics Engineering, ASCE, 121(2), 108-117.

Sorooshian, S., Gupta, V. K., \& Fulton, J. L. (1983). Evaluation of maximum likelihood parameter estimation techniques for conceptual rainfall - runoff models - influence of calibration data variability and length on 
model credibility. Water Resources Research, 19(1), 251-159.

US Army Corps of Engineers (USACE). (2000). Hydrologic Modelling System HEC-HMS, US Army Corps of Engineers, Hydrologic Engineering Center, March, 2000.

Wormleaton, A. J., \& Hadjipanos, P. (1982). Discharge Assessment in Compound Channel Flow. Journal of the Hydraulics Division, ASCE, 108, No. HY9:975-994.

\section{Copyrights}

Copyright for this article is retained by the author(s), with first publication rights granted to the journal.

This is an open-access article distributed under the terms and conditions of the Creative Commons Attribution license (http://creativecommons.org/licenses/by/4.0/). 